\title{
The efficacy of preoperative posterior subtenon injection of triamcinolone acetonide in noninfectious uveitic patients with secondary glaucoma undergoing trabeculectomy
}

\author{
This article was published in the following Dove Press journal: \\ Clinical Ophthalmology \\ Number of times this article has been viewed
}

\author{
Narumon Keorochana \\ Sutheera Kunasuntiwarakul \\ Isaraporn Treesit \\ Raveewan Choontanom \\ Department of Ophthalmology, \\ Phramongkutklao Hospital, \\ Phramongkutklao College of \\ Medicine, Bangkok, Thailand
}

Objective: The aim of this study was to evaluate the efficacy and safety of preoperative posterior subtenon injection of triamcinolone acetonide (PSTA) in noninfectious uveitic patients with secondary glaucoma undergoing primary trabeculectomy with mitomycin $\mathrm{C}$.

Design: This was a retrospective study.

Patients and methods: We reviewed the medical records of 10 noninfectious uveitic patients, who had received a single preoperative PSTA $40 \mathrm{mg} / 1 \mathrm{~mL}$, with secondary glaucoma undergoing primary trabeculectomy with mitomycin $\mathrm{C}$. We collected data before and after surgery on intraocular pressure (IOP), anterior chamber (AC) cells, best-corrected visual acuity (BCVA), morphologic characteristics of the filtering bleb and complications.

Results: The mean time between injection and surgery was $7.8 \pm 3.88$ days. Postoperative IOP level was significantly lower than preoperative level $(31.3 \pm 11.44 \mathrm{mmHg})$ at all visits $(P<0.02)$. Antiglaucoma medications were decreased from preoperative $(4.9 \pm 0.88)$ to 12 -month postoperative $(0.8 \pm 1.31 ; P$-value $<0.001)$ and also discontinued in seven eyes $(70 \%)$. About 12 months after surgery, eight eyes $(80 \%)$ with qualified success and two eyes $(20 \%)$ with failed treatment were recorded. AC cells and BCVA did not differ significantly from baseline; however, all inflammations were controlled successfully. Most desirable bleb morphology was shown at 12 months as well. Complications were blepharoptosis and hypotony maculopathy in two eyes $(20 \%)$.

Conclusion: A preoperative PSTA may be an effective and safe option in controlling intraocular inflammation and maintaining bleb function after trabeculectomy in noninfectious uveitic patients with secondary glaucoma during a 12-month period.

Keywords: periocular injection, steroid, uveitis, triamcinolone acetonide

\section{Introduction}

Uveitis is the inflammatory reaction of the middle, pigmented, vascular structures of the eye which includes the iris, ciliary body and choroid. Uveitis can be broadly categorized into infectious and noninfectious etiologies. The goal of the management of uveitis is to effectively control inflammation so as to eliminate or reduce the risk of vision loss from complications, such as secondary glaucoma, cataract, cystoid macular edema and hypotony. Corticosteroids are the mainstay of uveitis treatment. ${ }^{1}$

Uveitis can cause secondary glaucoma; however, corticosteroids that are the mainstay of uveitis treatment also cause secondary glaucoma. Trabeculectomy is indicated in patients whose maximum tolerated medical treatment fails to adequately reduce
Correspondence: Narumon Keorochana Department of Ophthalmology, Phramongkutklao Hospital, 3 I5 Rajawithi Road, Ratchathewi, Bangkok 10400 Thailand

Tel +6627633273

Fax +66 23549309

Email narumon_keo@hotmail.com 
intraocular pressure (IOP). The success of trabeculectomy is achieved through inhibiting the wound healing process, because the failure of trabeculectomy is usually due to excessive wound healing. ${ }^{2-5}$

The antimetabolites, 5-fluorouracil (5-FU) and mitomycin C (MMC), are widely used to inhibit wound healing in trabeculectomy, and it results in relatively avascular filtration blebs with less fibrovascular scarring and an increased success rate. ${ }^{3}$ However, corticosteroids also reduce and regulate wound healing through inhibition of macrophage functions such as phagocytosis and release of enzymes such as collagenase, plasminogen activator and growth factors and thus suppress inflammatory process for scar prevention. Postoperative topical corticosteroids have been used as an antifibrotic agent, and they increased the success rate of filtering surgery for a long period..$^{2-6}$ However, there is no literature review about preoperative medication for better outcome especially in uveitic patient who has more inflammation than usual.

Posterior subtenon injection of triamcinolone acetonide (PSTA) is generally given when a more posterior effect is needed or when a patient is noncompliant with unresponsive to topical or systemic administration. ${ }^{1}$ Subtenon injection of triamcinolone acetonide (TA $)^{2}$ is widely used to treat uveitis, because it is a high-efficacy and long-acting medication. So it might increase the success rate of trabeculectomy against secondary glaucoma. Tham et $\mathrm{al}^{6}$ reported the use of TA $1.2 \mathrm{mg}$ injected into filtration blebs at the end of trabeculectomy in a nonrandomized noncontrolled study and showed that good IOP control was obtained at least by the third month.

Limited data are available to support the safety and efficacy of PSTA among patients with uveitis undergoing trabeculectomy. We reviewed the efficacy of PSTA for controlling inflammation, visual improvement, success rate of trabeculectomy and the safety also in noninfectious uveitic and secondary glaucoma patients undergoing trabeculectomy with MMC.

\section{Patients and methods}

This was a retrospective case series study carried out between November 1, 2015, and April 1, 2017, at Phramongkutklao Hospital, Bangkok, Thailand. The study analyzed all patients with noninfectious uveitis and secondary glaucoma who had received a preoperative PSTA and undergone a primary trabeculectomy with MMC between January 1, 2014, and January 1, 2017.

We reviewed the cases in which patients with noninfectious uveitis with secondary glaucoma undergoing primary trabeculectomy with $\mathrm{MMC}$ received one preoperative PSTA, $40 \mathrm{mg}$ ( $1 \mathrm{~mL}$; Kanolone-F $\left.{ }^{\circledR}, 40 \mathrm{mg} / \mathrm{mL}\right)$. All injections were administered using the technique of Smith and Nozik (Figure 1). ${ }^{1}$ First, the conjunctiva is anesthetized with cotton swab soaked in tetracaine while patient looks inferonasally. Next syringe filled with triamcinolone and fitted with $25 / 26 \mathrm{G}$ needle is advanced with bevel facing toward the globe, superotemporally along the curve of the globe with intermittent sidewise sweeping movement to confirm the separation of needle from sclera. When the needle is advanced till the hub touches the conjunctiva, the plunger is slightly withdrawn to rule out injecting steroids within a vessel. Finally, triamcinolone is injected and needle is withdrawn. ${ }^{7}$ All patients were treated for intraocular inflammation at least 3 months before trabeculectomy.

The exclusion criteria were as follows: 1) patients $<18$ years or $>70$ years; 2) infectious uveitic patients; 3) pregnant or breastfeeding patients; 4) patients lost to follow-up; 5) incomplete data record.

Information on each patient was obtained from medical record review. Preoperative data obtained for each patients included age, sex, side of injected eye, type of uveitis, previous intraocular surgery, number of antiglaucoma medications, duration between PSTA and surgery, IOP (applanation tonometry), anterior chamber (AC) cells (the SUN (Standardization of Uveitis Nomenclature) working group grading scheme for $\mathrm{AC}$ cells ${ }^{8}$ ) and best-corrected visual acuity (BCVA; ETDRS visual acuity, logMAR).

Postoperative data, collected on 1 day, 1 week, 2 weeks and 1, 2, 3, 6, 9 and 12 months included IOP, AC cells, BCVA, the morphologic characteristics of the filtering bleb (the Indian Bleb Appearance Grading Scale ${ }^{9}$ ) and complications, that could be attributed to the PSTA, trabeculectomy or both, such as blepharoptosis, cataract

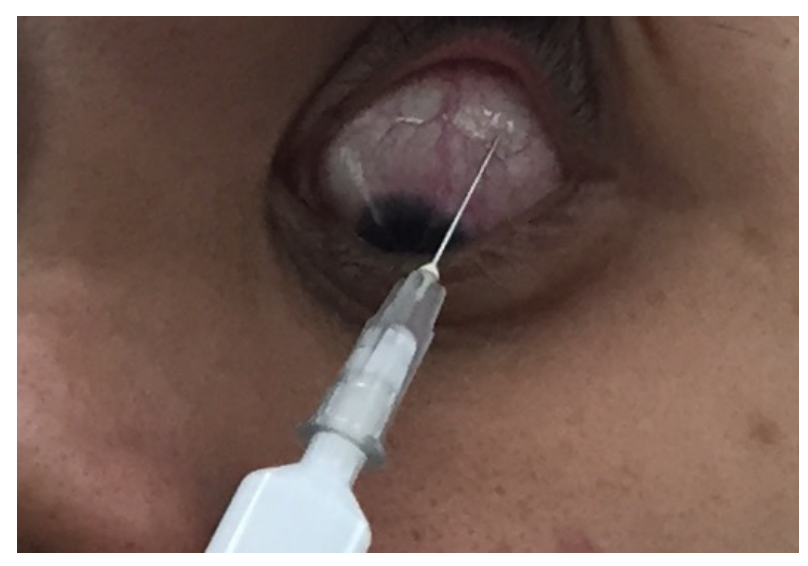

Figure I Posterior subtenon injection of triamcinolone acetonide. 
progression, cystoid macular edema, epiretinal membrane, hypotony maculopathy and infection.

Because patients were not seen on the same schedule after surgery, the following time points (with intervals) were established for data collection and analysis: 1 week \pm 2 days; 2 weeks \pm 3 days; 1 month \pm 5 days; 2 months \pm 1 week; 3 months \pm 2 weeks; 6 months \pm 4 weeks. No data were recorded for a patient at a given time point when the closest examination fell outside these established intervals.

Three primary outcome measures for IOP were defined. First, complete success was defined as having an IOP of $21 \mathrm{mmHg}$ or less or an IOP reduction of greater than or equal to $20 \%$ without antiglaucoma medication and intervention. Second, qualified success was defined as having an IOP of $21 \mathrm{mmHg}$ or less or an IOP reduction of greater than $20 \%$ with antiglaucoma medication and/or intervention performed at the slit lamp such as 5-FU injection, bleb needling procedures and laser suture lysis. Third, failed treatment was defined as having an IOP greater than $21 \mathrm{mmHg}$ despite medication (after the 3-month visit) or requiring reoperation for glaucoma surgery, hypotony or loss of light perception. Reoperation for glaucoma was defined as additional glaucoma surgery requiring a return to the operating room such as glaucoma drainage device or cyclodestructive procedure. Hypotony was defined as an IOP less than $5 \mathrm{mmHg}$. The secondary outcome measures were AC cells and BCVA.

Controlling inflammation was recorded as: 1) successful treatment, defined as AC cells, grade 0 and 0.5 , and 2) failed treatment, defined as AC cells, grade 1 or more.

Visual response was defined as: 1) improvement, defined as improving at least two lines of the ETDRS chart over baseline measurement, 2) deterioration, defined as deteriorating at least two lines of the ETDRS chart over baseline measurement and 3) no response, defined as improving or deteriorating less than two lines of the ETDRS chart over baseline measurement. The visual acuity on each visit was obtained using the patient's BCVA (logMAR).

Statistical analysis was performed using SPSS software version 23.0 (IBM Corporation, Armonk, NY, USA). Basic descriptive statistics were performed. The preoperative and postoperative IOP, AC cells and BCVA were analyzed using the paired $t$-test. A $P$-value of $<0.05$ was considered statistically significant.

This study was approved by the Phramongkutklao Institutional Review Board who have deemed that informed consent is not required when the patient cannot be identified, directly or through identifiers linked to the patient.

\section{Results}

In all, 13 patients with secondary glaucoma underwent primary trabeculectomy with MMC of which 13 patients had a confirmed diagnosis of noninfectious uveitis. After excluding patients with incomplete follow-up and incomplete records or those without a preoperative PSTA, a total of 10 patients were included for analysis.

The study population consisted of six males and four females with a mean age of $47.7 \pm 11.34$ years (range, 31-70 years). The mean preoperative PSTA and trabeculectomy surgery duration was $7.8 \pm 3.88$ days (1-16 days). The mean number of prescribed antiglaucoma medications dropped from a preoperative mean of $4.9 \pm 0.88$ (range, $3-6$ ) to a 12-month postoperative mean of $0.8 \pm 1.31$ (range, $0-3$; $P$-value $<0.001)$. Demographics and clinical characteristics are presented in Table 1.

The mean IOP at baseline was $31.3 \pm 11.44 \mathrm{mmHg}$, and mean IOPs at all visits are listed in Table 2. Postoperative IOP levels were significantly lower than preoperative levels at all visits $(P<0.02)$. About 12 months after surgery, eight eyes were considered to have a qualified success and two eyes were considered to have a failed treatment (Table 3).

Table I Demographics and clinical characteristics at baseline

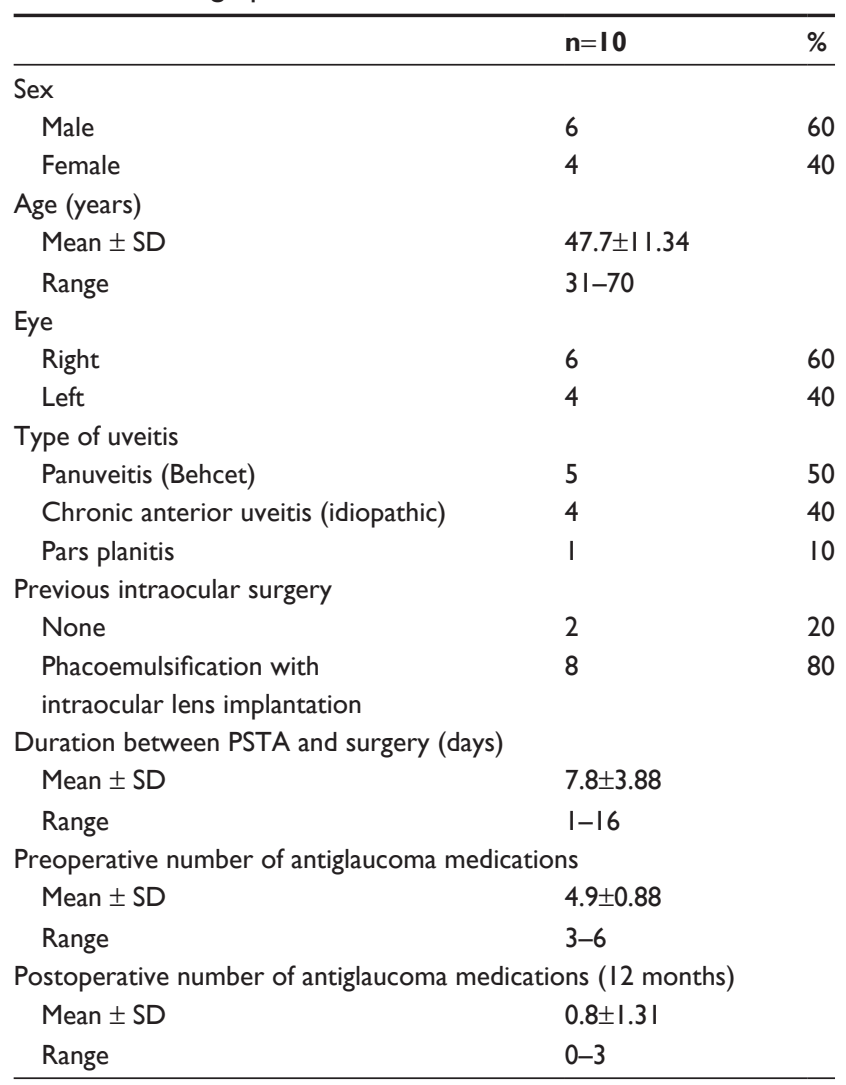

Abbreviation: PSTA, posterior subtenon injection of triamcinolone acetonide. 
Table 2 Mean IOP $(\mathrm{mmHg})$ compared to baseline at I day to 12 months

\begin{tabular}{lll}
\hline & Mean \pm SD & P-value \\
\hline Preoperative & $31.3 \pm 11.44$ & \\
I day & $19.3 \pm 5.79$ & 0.005 \\
I week & $14.8 \pm 6.63$ & 0.003 \\
2 weeks & $17.8 \pm 6.78$ & 0.019 \\
I month & $13.6 \pm 5.7$ & 0.001 \\
2 months & $13 \pm 4.67$ & 0.001 \\
3 months & $12.8 \pm 6.36$ & 0.001 \\
6 months & $12.1 \pm 4.46$ & 0.001 \\
9 months & $12.7 \pm 5.6 I$ & 0.001 \\
I2 months & $13.8 \pm 4.68$ & 0.001 \\
\hline
\end{tabular}

Notes: Paired $t$-test. Significant $(P<0.05)$.

Abbreviation: IOP, intraocular pressure.

The mean of AC cells at baseline was $0.15 \pm 0.34$. Mean AC cells at follow-up visits are presented in Table 4. About 12 months after surgery, AC cells did not differ significantly from baseline $(P=1.00)$, and all eyes were considered to be treated successfully.

The mean BCVA at baseline was $\log$ MAR $0.55 \pm 0.34$. Mean BCVA at follow-up visits is presented in Table 5. About 12 months after surgery, BCVA did not differ significantly from baseline ( $P=0.522)$. The visual acuity remain unchanged from baseline in $70 \%$ of patients, $20 \%$ of patients had improved VA and VA deteriorated in $10 \%$ of patients (Table 6).

The images of morphologic characteristics of filtering blebs at 1 month and 6 months after surgery are shown in Figures 2 and 3. The morphologic characteristics of the filtering blebs at 6 and 12 months after surgery were defined in terms of the Indiana Bleb Appearance Grading Scale as shown in Table 7. The complications that could be attributed to the PSTA, trabeculectomy or both are presented in Table 3. One patient had experienced blepharoptosis, and one patient had a diagnosis of hypotony maculopathy. No patients experienced cataract progression, cystoid macular edema, epiretinal membrane or infection.

\section{Discussion}

Most glaucoma filtering surgical failure in uveitis occurs because of scarring in the subconjunctival space by the excessive ocular wound healing response from inflammation. Modulation of the wound healing process to prevent excessive fibroblast proliferation and scar formation can play a major role in improving the outcome of trabeculectomy. A common clinical practice is to administer intraoperative $\mathrm{MMC}$, and postoperative 5-FU is recommended for high-risk patients. However, the use of 5-FU and MMC is associated

Table 3 Data of previous intraocular surgery, number of antiglaucoma medications, IOP at 12 months after surgery, additional intervention after surgery, outcome measurement and complications

\begin{tabular}{|c|c|c|c|c|c|c|c|c|}
\hline \multirow[t]{2}{*}{$\begin{array}{l}\text { Code } \\
\text { no }\end{array}$} & \multirow{2}{*}{$\begin{array}{l}\text { PAS } \\
\text { extension } \\
\text { (clock's hour) }\end{array}$} & \multirow{2}{*}{$\begin{array}{l}\text { Previous } \\
\text { intraocular } \\
\text { surgery }\end{array}$} & \multicolumn{2}{|c|}{$\begin{array}{l}\text { Number of antiglaucoma } \\
\text { medications }\end{array}$} & \multirow{2}{*}{$\frac{\text { IOP }}{12 \text { months }}$} & \multirow[t]{2}{*}{$\begin{array}{l}\text { Additional intervention } \\
\text { after surgery }\end{array}$} & \multirow[t]{2}{*}{$\begin{array}{l}\text { Outcome } \\
\text { measurement }\end{array}$} & \multirow[t]{2}{*}{ Complications } \\
\hline & & & Preoperative & 12 months & & & & \\
\hline I & 0 & $\mathrm{PE} / \mathrm{IOL}$ & 4 & 0 & 13 & LSL at 2 weeks & Qualified success & - \\
\hline 2 & 0 & $\mathrm{PE} / \mathrm{IOL}$ & 6 & 0 & 8 & $\begin{array}{l}5 \text {-FU injection } 5 \mathrm{mg} / 0.1 \mathrm{~mL} \\
\text { at I week }\end{array}$ & Qualified success & Blepharoptosis \\
\hline 3 & 2 & - & 5 & 0 & 11 & $\begin{array}{l}\text { LSL at I day, bleb needling with } \\
5 \text {-FU } 5 \mathrm{mg} / 0.1 \mathrm{~mL} \text { at } 3 \text { months }\end{array}$ & Qualified success & - \\
\hline 4 & 0 & - & 5 & 2 & 23 & $\begin{array}{l}\text { Resuturing conjunctiva at } \\
2 \text { days, } L S L \text { at I month }\end{array}$ & Failed treatment & - \\
\hline 5 & 4 & $\mathrm{PE} / \mathrm{IOL}$ & 5 & 0 & 12 & $\begin{array}{l}\text { LSL at I week, bleb needling } \\
\text { with } 5 \text {-FU } 5 \mathrm{mg} / 0.1 \mathrm{~mL} \text { at } \\
\text { I and } 2 \text { weeks }\end{array}$ & Qualified success & - \\
\hline 6 & 0 & $\mathrm{PE} / \mathrm{IOL}$ & 3 & 0 & 8 & LSL at I day & Qualified success & - \\
\hline 7 & 8 & $\mathrm{PE} / \mathrm{IOL}$ & 6 & 0 & 15 & LSL at I day and I week & Qualified success & - \\
\hline 8 & 3 & $\mathrm{PE} / \mathrm{IOL}$ & 5 & 0 & 13 & LSL at I day & Qualified success & - \\
\hline 9 & 5 & $\mathrm{PE} / \mathrm{IOL}$ & 5 & 3 & 16 & $\begin{array}{l}\text { Resutured scleral flap with } \\
\text { reformed } A C \text { with viscoelastic } \\
\text { agent at } 4 \text { days }\end{array}$ & Failed treatment & $\begin{array}{l}\text { Hypotony } \\
\text { maculopathy }\end{array}$ \\
\hline 10 & 9 & $\mathrm{PE} / \mathrm{IOL}$ & 5 & 3 & 19 & $\begin{array}{l}\text { LSL at I day and I month, } \\
\text { bleb needling with } 5 \text {-FU } \\
5 \mathrm{mg} / 0.1 \mathrm{~mL} \text { at } 2 \text { and } 3 \text { weeks }\end{array}$ & Qualified success & - \\
\hline
\end{tabular}

Abbreviations: AC, anterior chamber; 5-FU, 5-fluorouracil; IOP, intraocular pressure; LSL, laser suture lysis; PAS, peripheral anterior synechiae; PE/IOL, phacoemulsification with intraocular lens implantation. 
Table 4 Mean AC cells grading compared to baseline at I day to 12 months

\begin{tabular}{lll}
\hline & Mean \pm SD & P-value \\
\hline Preoperative & $0.15 \pm 0.34$ & \\
I day & $1.9 \pm 0.74$ & $<0.00$ I \\
I week & $0.55 \pm 0.64$ & 0.022 \\
2 weeks & $0.3 \pm 0.35$ & 0.193 \\
I month & $0.05 \pm 0.16$ & 0.168 \\
2 months & $0.15 \pm 0.34$ & 1.000 \\
3 months & $0.0 \pm 0.0$ & 0.195 \\
6 months & $0.15 \pm 0.24$ & 1.000 \\
9 months & $0.05 \pm 0.16$ & 0.443 \\
I2 months & $0.15 \pm 0.24$ & 1.000 \\
\hline
\end{tabular}

Notes: Paired $t$-test. Significant $(P<0.05)$.

Abbreviation: AC, anterior chamber.

with corneal epithelial defects, wound leaks and hypotony with accompanying vision loss. Nowadays, the use of growth factors such as antibodies, cyclosporine and antifibrinolytic agents such as urokinase and recombinant tissue plasminogen activator adds a new and controversial dimension to postoperative pharmacologic therapy. ${ }^{11-18}$

Many studies have reported the success rate of trabeculectomy after using postoperative steroids for better glaucoma control,, 45 especially the use of topical steroids..$^{10}$ However, little data are available on the efficacy of preoperative PSTA before glaucoma surgery. Tham et $\mathrm{l}^{6}$ published a nonrandomized noncontrolled study using intra-bleb TA $(1.2 \mathrm{mg})$ injected at the end of trabeculectomy in 11 eyes. They demonstrated that injecting TA directly into the bleb provides a good IOP control at least by the third month and appears to be safe up to 3 months after surgery, without the evidence of increased cataract formation.

Wang et $\mathrm{al}^{19}$ showed that intracameral TA injection during combined phacoemulsification with trabeculectomy significantly reduced aqueous inflammation and improved

Table 5 Mean visual acuity compared to baseline at I day to 12 months

\begin{tabular}{lll}
\hline & Mean \pm SD & P-value \\
\hline Preoperative & $0.55 \pm 0.34$ & \\
I day & $0.64 \pm 0.37$ & 0.350 \\
I week & $0.61 \pm 0.37$ & 0.239 \\
2 weeks & $0.58 \pm 0.37$ & 0.656 \\
I month & $0.43 \pm 0.27$ & 0.081 \\
2 months & $0.42 \pm 0.33$ & 0.022 \\
3 months & $0.44 \pm 0.31$ & 0.032 \\
6 months & $0.51 \pm 0.34$ & 0.522 \\
9 months & $0.55 \pm 0.41$ & 1.000 \\
I2 months & $0.50 \pm 0.33$ & 0.537 \\
\hline
\end{tabular}

Notes: Paired $t$-test. Significant $(P<0.05)$.
Table 6 Outcome measurement of visual response (BCVA) compared to baseline at 12 months

\begin{tabular}{llll}
\hline $\begin{array}{l}\text { Code } \\
\text { no }\end{array}$ & $\begin{array}{l}\text { Preoperative } \\
\text { (logMAR) }\end{array}$ & $\begin{array}{l}\text { Month } \\
\mathbf{I 2}\end{array}$ & $\begin{array}{l}\text { Outcome } \\
\text { measurement }\end{array}$ \\
\hline 1 & 0.70 & 0.20 & Improvement \\
2 & 0.30 & 0.70 & Deterioration \\
3 & 0.10 & $>1$ & No response \\
4 & 0.20 & 0.40 & No response \\
5 & 0.90 & 0.60 & Improvement \\
6 & 0.20 & 0.20 & No response \\
7 & 0.60 & 0.50 & No response \\
8 & $>1$ & $>1$ & No response \\
9 & 0.50 & 0.40 & No response \\
10 & $>1$ & $>1$ & No response \\
\hline
\end{tabular}

Abbreviation: BCVA, best-corrected visual acuity.

visual acuity. However, a study by Yuki et $\mathrm{al}^{20}$ showed that trabeculectomy with intraoperative subtenon injection of TA to treat secondary glaucoma neither increased the intermediate-term success rate nor decreased postoperative complications at 12 months.

In our series, the postoperative IOP levels were significantly lower than preoperative levels at all visits $(P<0.02)$. Eight of 10 patients $(80 \%)$ were considered to have a qualified success at 12 months. Two patients were classified as failure of treatment. One patient required resuturing the conjunctiva due to bleb leakage. Another one required resuturing the scleral flap with reformed AC with viscoelastic agent due to overfiltration. The leaking bleb occurring at the early postoperative period could be due to poor surgical technique, differing from late leaking bleb, which caused avascular, thin wall bleb in MMC-augmented trabeculectomy. The overfiltration at the early postoperative period could also be due to poor surgical technique, rather than the effect of long-term steroid use.

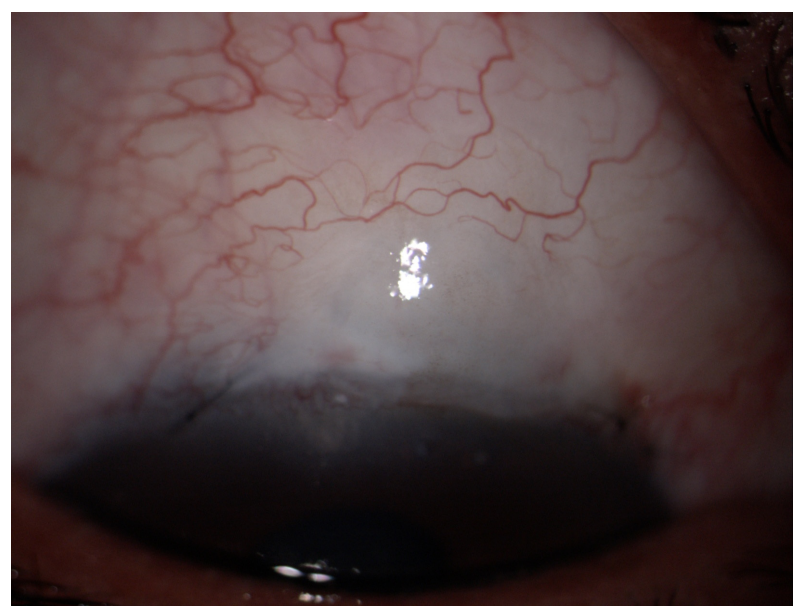

Figure 2 Morphologic characteristics of diffuse low-lying, avascular anterior bleb at I month after surgery. 


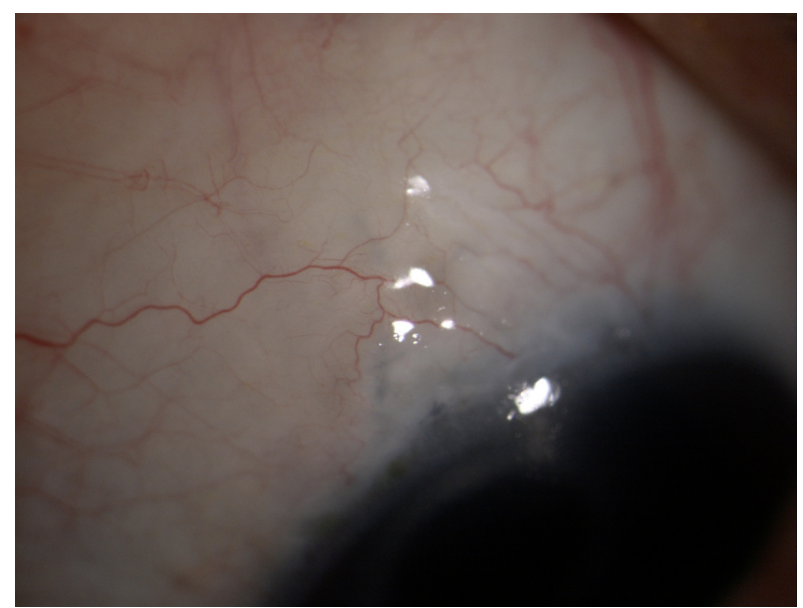

Figure 3 Diffuse, low-lying, normal vascular bleb at 6 months after surgery.

One patient received 5-FU $5 \mathrm{mg} / 0.1 \mathrm{~mL}$ injection, and three patients received bleb needling with 5 -FU $5 \mathrm{mg} / 0.1 \mathrm{~mL}$ injection due to bleb inflammation, which was high-risk for bleb failure, as part of the wound healing response. A total of seven patients experienced laser suture lysis from tight sutures. Uveitic patients undergoing trabeculectomy with antifibrotic agents are at particularly high risk for developing postoperative hypotony, so tight suturing of the sclera flap is recommended. ${ }^{21}$

We also found AC cells and BCVA did not differ significantly from baseline ( $P=1.00$ and 0.537 , respectively) at 12 months after surgery were considered successful treatments. The results could be due to the anti-inflammatory properties of corticosteroid injection, even though the approximate duration of action of TA was 2-4 months. Reducing inflammation also helped to maintain bleb function, as well as preoperative PSTA.

Complications that could be attributed to the PSTA, trabeculectomy or both include blepharoptosis, cataract progression, hypotony maculopathy, cystoid macular edema, epiretinal membrane and infection. In our series, one patient experienced blepharoptosis and another experienced hypotony maculopathy due to overfiltration that improved over time. These could indicate the safety of preoperative PSTA.

Table 7 The morphologic characteristics of the filtering blebs at 6 and 12 months after surgery

\begin{tabular}{llll}
\hline & $\begin{array}{l}\text { 6 months } \\
\text { (mean } \pm \text { SD) }\end{array}$ & $\begin{array}{l}\text { I2 months } \\
\text { (mean } \pm \text { SD) }\end{array}$ & Range \\
\hline Height & $1.6 \pm 0.69$ & $1.4 \pm 0.70$ & $1-3$ \\
Horizontal extent & $2.7 \pm 0.48$ & $2.00 \pm 0.82$ & $2-3$ \\
Vascularity & $1.9 \pm 0.56$ & $1.20 \pm 0.63$ & $1-3$ \\
Leakage & 0 & 0 & 0 \\
\hline
\end{tabular}

Filtering surgery such as trabeculectomy is less successful among patients with uveitis because of the younger age of such patients and inflammatory mediators that promote fibrous tissue growth and closure of the filtering bleb. ${ }^{22}$

Corticosteroids used to manage ocular inflammation are factors that have an effect on visual outcomes. Well-managed inflammation can prevent postoperative complications. In a comparative study by Ghate et al, ${ }^{23}$ posterior subtenon injection was the best periocular route for vitreous delivery with minimal systemic levels. In addition, posterior subtenon corticosteroid injection has great therapeutic features to manage inflammation.

TA is an anti-inflammatory drug, so the effect of TA for filtering surgery seems to be effective for inflammatory glaucoma such as uveitic glaucoma similar to our study, whereas the administration of TA through the subtenon route could be highly variable and difficult to assess, as the diffusion of the drug into the eye is by the sclera and the choroid. Despite the favorable results, our study had some limitations. The study had small sample size and no control group; this was a retrospective study; and all surgeries were performed by glaucoma specialists or glaucoma fellowship trainers.

\section{Conclusion}

The results of this study suggest that a preoperative PSTA may be an effective and safe option in controlling intraocular inflammation and maintaining bleb function after primary trabeculectomy with MMC in noninfectious uveitic patients with secondary glaucoma at a 12 -month period. No evidence is currently available to suggest a routine preoperative PSTA use before glaucoma surgery among uveitic patients. We would recommend further randomized controlled studies to develop more validity and reliability of this treatment.

\section{Acknowledgment}

The authors are thankful to Mrs Supak Caengow, Phramongkutklao College of Medicine for research statistical assistance.

\section{Disclosure}

The authors report no conflicts of interest in this work.

\section{References}

1. Skuta GL, Cantor LB, Weiss JS. Clinical approach to uveitis. Intraocular Inflammation and Uveitis 2012-2013. San Francisco, CA: American Academy of Ophthalmology; 2012:100-103.

2. Hosseini H, Mehryar M, Farvardin M. Focus on triamcinolone acetonide as an adjunct to glaucoma filtration surgery. Med Hypotheses. 2007; 68(2):401-403.

3. Lama PJ, Fechtner RD. Antifibrotics and wound healing in glaucoma surgery. Surv Ophthalmol. 2003;48(3):314-346. 
4. Araujo SV, Spaeth GL, Roth SM, Starita RJ. A ten-year follow-up on a prospective, randomized trial of postoperative corticosteroids after trabeculectomy. Ophthalmology. 1995;102(12):1753-1759.

5. Roth SM, Spaeth GL, Strarita RJ, Birbillis EM, Steinmann WC. The effects of postoperative corticosteroids on trabeculectomy and the clinical course of glaucoma: five-year follow-up study. Ophthalmic Surg. 1991;22(12):724-729.

6. Tham CC, Li FC, Leung DY, et al. Intrableb triamcinolone acetonide injection after bleb-forming filtration surgery (trabeculectomy, phacotrabeculectomy, and trabeculectomy revision by needling): a pilot study. Eye (Lond). 2006;20(12):1484-1486.

7. Venkatesh P, Kumar CS, Abbas Z, Garg S. Comparison of the efficacy and safety of different methods of posterior subtenon injection. Ocul Immunol Inflamm. 2008;16(5):217-223.

8. Jabs DA, Nussenblatt RB, Rosenbaum JT; Standardization of Uveitis Nomenclature (SUN) Working Group. Standardization of uveitis nomenclature for reporting clinical data. Results of the first international workshop. Am J Ophthalmol. 2005;140(3):512.

9. Cantor LB, Mantravadi A, WuDunn D, Swamynathan K, Cortes A. Morphologic classification of filtering blebs after glaucoma filtration surgery: the Indiana Bleb Appearance Grading Scale. J Glaucoma. 2003;12(3):266-271.

10. Starita RJ, Fellman RL, Spaeth GL, Poryzees EM, Greenidge KC, Traverso CE. Short- and long-term effects of postoperative corticosteroids on trabeculectomy. Ophthalmology. 1985;92(7):938-946.

11. Lee DA. Antifibrosis agents and glaucoma surgery. Invest Ophthalmol Vis Sci. 1994;35(11):3789-3791.

12. Khaw PT, Migdal CS. Current techniques in wound healing modulation in glaucoma surgery. Curr Opin Ophthalmol. 1996;7(2):24-33.

13. Yoon PS, Singh K. Update on antifibrotic use in glaucoma surgery, including use in trabeculectomy and glaucoma drainage implants and combined cataract and glaucoma surgery. Curr Opin Ophthalmol. 2004;15(2):141-146.
14. Chen PP, Yamamoto T, Sawada A, Parrish RK, Kitazawa Y. Use of antifibrosis agents and glaucoma drainage devices in the American and Japanese Glaucoma Societies. J Glaucoma. 1997;6(3):192-196.

15. Donohue EK, Cioffi GA. Glaucoma surgery: are there new perspectives in perioperative pharmacology? Curr Opin Ophthalmol. 1999; 10(2):93-98.

16. Szaflik J, Zaleska-Zmijewska A. Pharmacological methods improving the effectiveness of filtering procedures. Klin Oczna. 2004;106: 273-278.

17. Lattanzio FA Jr, Crouch ER Jr, Mitrev PV, Williams PB, Allen RC. Cyclosporin as an adjunct to glaucoma filtration surgery. J Glaucoma. 2005;14(6):441-447.

18. Joshi AB, Parrish RK 2nd, Feuer WF. 2002 survey of the American Glaucoma Society: practice preferences for glaucoma surgery and antifibrotic use. J Glaucoma. 2005;14(2):172-174.

19. Wang B, Dong N, Xu B, Liu J, Xiao L. Efficacy and safety of intracameral triamcinolone acetonide to control postoperative inflammation after phacotrabeculectomy. J Cataract Refract Surg. 2013; 39(11):1691-1697.

20. Yuki K, Shiba D, Kimura I, Ohtake Y, Tsubota K. Trabeculectomy with or without intraoperative sub-tenon injection of triamcinolone acetonide in treating secondary glaucoma. Am J Ophthalmol. 2009;147(6):10551060, 1060.e1-e2.

21. American Academy of Ophthalmology. Management of Elevated IOP in Patients with Uveitis. San Francisco, CA: American Academy of Ophthalmology Governmental Affairs Division; 2016.

22. Nussenblatt RB, Whitcup SM. Uveitis: Fundamentals and Clinical Practice. 4th ed. St. Louis: Elsevier Health Sciences; 2010:120.

23. Ghate D, Brooks W, McCarey BE, Edelhauser HF. Pharmacokinetics of intraocular drug delivery by periocular injections using ocular fluorophotometry. Invest Ophthalmol Vis Sci. 2007;48(5):2230-2237.
Clinical Ophthalmology

\section{Publish your work in this journal}

Clinical Ophthalmology is an international, peer-reviewed journal covering all subspecialties within ophthalmology. Key topics include: Optometry; Visual science; Pharmacology and drug therapy in eye diseases; Basic Sciences; Primary and Secondary eye care; Patient Safety and Quality of Care Improvements. This journal is indexed on Submit your manuscript here: http://www.dovepress.com/clinical-ophthalmology-journal

\section{Dovepress}

PubMed Central and CAS, and is the official journal of The Society of Clinical Ophthalmology (SCO). The manuscript management system is completely online and includes a very quick and fair peer-review system, which is all easy to use. Visit http://www.dovepress.com/ testimonials.php to read real quotes from published authors. 